\title{
Animation and Prototyping as Tools for Teaching Project in Architecture
}

\section{SIGRADI2018 TECHNOPOLITICAS \\ xxii congresso da sociedade iberoamericana de gráfica digital 22th conference of the iberoamerican society of digital graphics 07|08|09|novembro|2018 iau usp | são carlos | sp br}

\author{
Patrícia Turazzi Luciano \\ Universidade Federal de Santa Catarina | Brazil | patriciaturazzi@gmail.com \\ Carla Cristina Secchi \\ Universidade Federal de Santa Catarina | Brazil | cah_secchi@unochapeco.edu.br
}

Carlos Eduardo Verzola Vaz

Universidade Federal de Santa Catarina | Brazil | cevv00@gmail.com

\begin{abstract}
The research explored the use of animation and prototyping as a tool to aid in the materialization and development of project ideas, not just as a means of presenting the final project. The article brings the elaboration, application and results obtained from a seven-day workshop with a group of students of the third year of graduation of the course of Architecture and Urbanism.
\end{abstract}

Keywords: Architectural Design Process; Animation; Prototyping; Teaching.

\section{INTRODUÇÃO}

A habilidade de representação está associada à capacidade de alcançar soluções de projeto, assim, Pina, Borges Filho e Marangoni (2011) afirmam que a maquete e 0 desenho são fundamentais dentro do desenvolvimento de projetos, uma vez que através desses instrumentos se amplia a compreensão de problemas arquitetônicos e das soluções possíveis. $O$ momento de dar forma às ideias de projeto exige duas habilidades essenciais do projetista: a movimentação, relacionada à criação de diversas soluções de projeto; e a representação, habilidade pela qual se produz os movimentos no processo de projeto (Andrade, Ruschel, \& Moreira, 2011). Portanto, quanto maior e mais diversificada a habilidade de representação de ideias que um projetista possui, maior é sua capacidade de desenvolver e responder aos problemas de projeto.

A carta para a educação dos Arquitetos (UIA, 2011), em suas considerações gerais, declara que os métodos de formação e aprendizagem para os arquitetos sejam diversificados, prevendo uma variedade de métodos para enriquecer o ateliê de projeto e recomendando um ensino flexível. Dessa forma, a disponibilidade de novas ferramentas no ateliê de projeto para auxiliar o educando de arquitetura a materializar suas ideias é relevante como novas formas de expressão e de entendimento de demandas e problemas diversos.

A animação, por um lado, é a arte em movimento (Laybourne, 1998), e tem no movimento sua essência, para além das ilustrações e gravuras. A animação se desenvolveu e se popularizou juntamente com o cinema e desde então surgiram diversas técnicas, mas que podem ser classificadas em 3 categorias básicas (Lord \& Sibley, 2015). Algumas das técnicas já vêm sendo aplicadas na área da arquitetura, como exposto por Dollens (2006) e Zarin, Lindbergh e Fallman (2012).
A prototipagem digital e seu potencial de aplicação na arquitetura tem sido discutido na academia ao longo de vários anos (Nardelli, 2014), sendo mais popularmente conhecida pela atual expansão dos FABLABs fabrication laboratory, que possibilitam uma maior aproximação de técnicas e maquinários com os discentes. A prototipagem digital pode ser considerada como uma grande aliada nos desafios projetuais, possuindo como vantagem a possibilidade de visualização do modelo físico, permitindo a compreensão espacial com rapidez (Pupo, 2008). Ainda de acordo com a autora, a prototipagem digital pode ser conceituada como um método de produção automatizada por computador, para produção de protótipos.

Outro ponto defendido pela carta para a educação dos Arquitetos (UIA, 2011) refere-se aos objetivos da formação em arquitetura, constando a compreensão das relações existentes entre pessoas e espaços construídos, e esse com seu entorno. O conceito de lugar abrange as dinâmicas humanas e não humanas que ocorrem no espaço (Alexander, 1979). Essa dinamicidade é um aspecto difícil de ser devidamente explorado e representado com as ferramentas tradicionais de desenho e maquetes. Contudo, ainda que a maquete seja uma representação estática, a animação, que tem no movimento sua essência, pode simular essas dinâmicas, ou seja, com ambas ferramentas (maquete e animação) temos a simulação do caráter do lugar.

A animação e a prototipagem propiciam novas maneiras de expressão com respostas mais criativas, dando novos usos para maquetes e desenhos considerados fundamentais (Pina, et al., 2011), pois auxilia na compreensão e avaliação arquitetônica (Batistello, Balzan, Piaia, \& Miotto, 2015).

O objetivo desta pesquisa é explorar o uso da animação stop motion como método de representação de conceitos de projeto por parte dos estudantes de arquitetura e 
Urbanismo. Neste tipo de animação, é necessária a criação de elementos que irão compor os cenários. Logo, propõe-se a utilização de técnicas de prototipagem para a materialização, não apenas dos elementos que compõem o projeto, mas do ferramental necessário para a confecção das animações. Além disso, durante o processo de investigação, foram explorados diferentes tipos de aplicativos capazes de auxiliar na coleta de imagens e edição de vídeos. Como será visto, a pesquisa envolveu a realização de uma oficina com discentes de Arquitetura e Urbanismo, na qual produziram curta metragens. A partir dos resultados dessa pesquisa, pretende-se compreender como a animação e a prototipagem podem contribuir, de forma conjunta, no ensino da arquitetura e urbanismo.

\section{MÉTODOS}

A pesquisa está dividida em 3 etapas conforme mostra o fluxograma da figura 1.

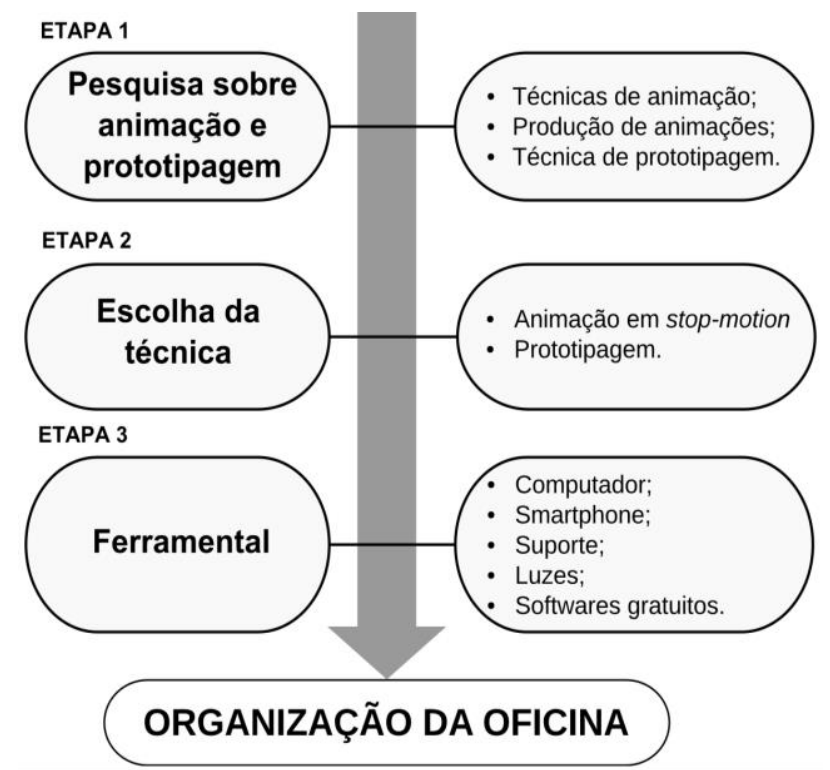

Figura 1: Etapas para elaboração da oficina. Fonte: autoria própria.

A primeira etapa - pesquisa sobre animação e prototipagem, teve três eixos, primeiro estudou-se sobre as técnicas básicas de animação existentes, como é a produção de cada uma e qual o ferramental básico para gerá-las. Segundo pesquisou-se sobre animação utilizada no ensino de projeto procurando conhecer as experiências já realizadas com animação durante o processo de projeto, ou seja, usada para desenvolver ideias e não apenas como representação final da solução projetual. Essas experiências foram estudadas visando compreender como as animações foram utilizadas, com que objetivo e quais foram os resultados alcançados. Em terceiro, a prototipagem foi estudada, buscando entender como ocorre a integração entre métodos manuais e digitais de desenvolvimento de projeto e representação em ateliês.

Na segunda etapa, foi escolhida a técnica de animação e de prototipagem que seriam utilizadas durante a oficina, com base na revisão bibliográfica e nas necessidades específicas do estudo de caso. Como será visto a seguir, existem três técnicas básicas de animação, das quais duas já foram aplicadas no ensino de projeto de arquitetura. Quanto a prototipagem, existem cinco principais técnicas de prototipagem digital disponíveis nos FABLABs.

$\mathrm{Na}$ terceira etapa, levantou-se todo o ferramental necessário para a produção de uma animação na técnica stop motion com auxílio da prototipagem.

\section{ANIMAÇÃO E PROTIPAGEM APLICADAS AO ENSINO DE PROJETO}

Como explicado anteriormente, a animação é um filme em que cada fotograma é produzido individualmente a partir de computação gráfica ou fotografias, existindo três tipos básicos:

a. Animação bidimensional: trabalha com desenhos sobrepostos que são fotografados quadro a quadro, sendo necessário um desenho para cada quadro da animação;

b. Animação tridimensional: ou stop motion, consiste em fotografar modelos em miniatura um quadro do filme por vez e ajustar suas posições para a próxima fotografia, dando a impressão final, quando o filme é mostrado, que o modelo se movimenta sozinho;

c. Animação digital: é produzida por meio de softwares específicos, tanto em duas quanto em três dimensões.

A revisão teórica sobre o uso da animação para o ensino de projeto de arquitetura teve escassez de estudos referenciais, e, portanto, foi ampliada, de forma a abarcar o ensino de projeto em Design, uma vez que o ensino de projeto em ambas as especializações é correlato. Trabalhos recentes focam no uso do desenho em associação com várias outras mídias expressivas, como vídeo (Ylirisky \& Buur 2007) e a programação (Lindell, 2012). Especialistas da área do design, como Lindell (2012) e Vistisen (2016) relatam que a falta de informação temporal torna difícil preencher todas as lacunas de um esboço pelo desenho, apontando a animação como uma prática a ser estudada na área do projeto do produto.

Pesquisadores de diferentes áreas exploraram o uso da animação na última década. Dollens (2006), por meio da produção de um curta-metragem intitulado "The Cathedral', ilustra o potencial da animação digital como ferramenta que pode ser usado no desenvolvimento de projeto de arquitetura e não apenas para apresentação do produto final. Bonanni e Ishii (2009) realizaram dois exercícios: um deles em vídeo e outro em animação stop motion dentro de oficinas da área do design, chegando à conclusão de que as animações foram especialmente úteis no desenvolvimento conceitual. Eikenes e Morrison (2010) chegaram a uma conclusão semelhante quando aplicaram o movimento animado por computador para explorar interações de interface, assim como Fallman e Moussette (2011), que debatem sobre o desenvolvimento de projetos dentro do design de interação com o auxílio da animação em stop motion, com aplicação de uma oficina para mestrandos em design. Zarin et al. (2012) aplicaram a animação stop motion em um workshop com estudantes, concluindo que o desenho pode não ser tão eficiente para capturar as características temporais, como o fluxo de pessoas através de uma edificação ou como uma arquitetura decai ao longo do tempo. Segundo os pesquisadores prévios, o esboço de projeto baseado em animação mostrou potencial como uma ferramenta que abrange o esboço temporal e narrativo de um projeto; apesar disso, apenas dois experimentos foram realizados 
com graduandos de Arquitetura e Urbanismo (Dollens, 2006; Zarin et al., 2012).

A prototipagem digital é utilizada e aplicada em muitos casos no ensino e ateliê de projeto. O Digital Design Fabrication Group, do Massachusetts Institute of Technology (MIT) trabalha constantemente em pesquisas envolvendo habitações, ensino e tecnologias digitais, coordenado por Lawrence Sass. Um dos laboratórios de referência em prototipagem aplicada à área da Arquitetura e Urbanismo é o LAPAC - Laboratório de Automação e Prototipagem para Arquitetura e Construção da Faculdade de Arquitetura e Urbanismo da UNICAMP, coordenado pela professora Maria Gabriela Caffarena Celani. A partir de suas pesquisas, novos centros foram sendo formados no Brasil, como por exemplo, a Rede Pronto 3D, coordenado pela professora Regiane Pupo. Nesses laboratórios, podem ser encontrados equipamentos de corte a laser, impressoras 3D ou CNCs (máquinas de comando numérico computadorizado), sendo utilizados em sua maioria para a elaboração de modelos ou protótipos nas mais diferentes áreas. Sass (2008), enfatiza o uso das tecnologias digitais como uma metodologia de ensino de projeto, onde kits de construção feitos a partir de prototipagem rápida foram fornecidos aos alunos para montagem de estruturas. De acordo com o autor, o modelo físico amplia as possibilidades de projeto e criatividade, para além das somente visuais em softwares. Pupo (2009) em sua tese de doutorado, realizou workshops sobre teoria e prática da prototipagem, e utilizou-se impressora 3D e corte a laser.

\section{SELEÇÃO DAS TÉCNICAS DE ANIMAÇÃO E PROTOTIPAGEM}

Existem duas técnicas de animação já aplicadas no ensino de projeto de arquitetura, como abordado anteriormente. As animações digitais que demandam equipamento e licenças de softwares, além de ser um trabalho realizado individualmente (Dollens, 2006), e a animação tridimensional que não demanda um grande investimento em equipamentos e licenças (Bonanni \& Ishii, 2009; Fallman \& Moussette, 2011; Zarin et al., 2012).

Com o referencial teórico sobre animação levantou-se as três técnicas básicas (Lord \& Sibley, 2015): Animação bidimensional; Animação tridimensional; e Animação digital. Para eleger a técnica a ser utilizada na oficina foram avaliados três critérios:

a. Técnica de animação direta, onde o animador desenha ou capta um movimento após o outro até chegar a pose final da cena, não planejando exatamente como vai ser o decorrer da cena e vai criando à medida em que progride;

b. Equipamentos acessíveis com programas/aplicativos gratuitos;

c. Animação que favoreça o trabalho em grupo.

Assim, a animação digital e a animação bidimensional apenas cumpriam o requisito de equipamento acessível e foram descartadas, optando-se por utilizar a animação tridimensional, mais conhecida como stop motion, o que foi condizente com a escolha de outros pesquisadores que elegeram trabalhar com a técnica pela facilidade de acesso (Bonanni \& Ishii, 2009; Fallman \& Moussette, 2011; Zarin et al., 2012).

\section{FERRAMENTAL NECESSÁRIO PARA A OFICINA}

Segundo Lord e Sibley (2015), o equipamento básico para um estúdio de stop motion é muito simples: uma câmera; um computador; um tripé para suportar a câmera; uma superfície plana onde ocorrerá a ação; algumas luzes para garantir um nível de luz imutável durante a animação, além do cenário e personagens. Esse foi o aparato com que os fundadores dos estúdios Aardman Animations (Lord \& Sibley, 2010) começaram suas animações; por conseguinte, esse ferramental básico foi estabelecido tendo como essência a animação, ou seja, como meio de estabelecer uma boa qualidade para a animação em si. Nesta pesquisa a animação não é um fim, mas um meio pelo qual pode-se expressar as qualidades do projeto. Dessa forma, o ferramental básico necessário foi listado:

a. Smartphone - para a captura das imagens;

b. Computador - para posterior edição e inserção de legendas;

c. Suporte de celular - para possibilitar a fixação do smartphone em ângulo específico;

d. Luminárias.

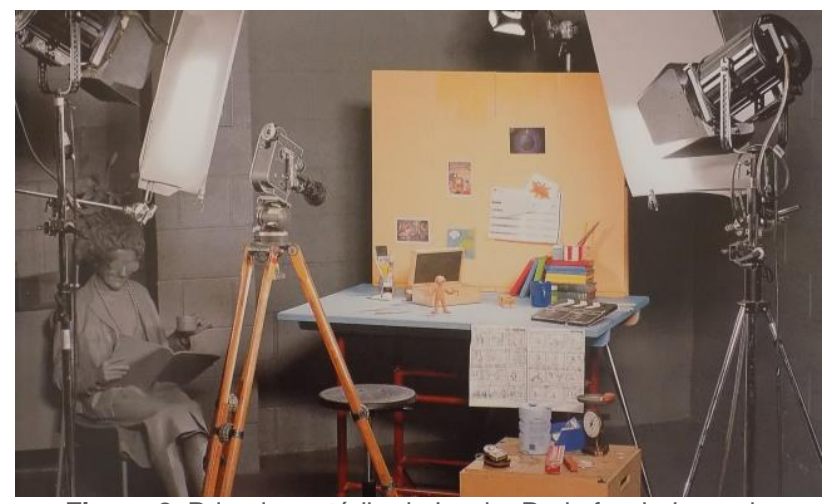

Figura 2: Primeiro estúdio de Lord e Park, fundadores da Aardman. Fonte: Lord e Sibley (2010)

A oficina foi planejada para que os participantes trabalhassem em equipes, supondo-se que cada agrupamento possuiria ao menos um smartphone, um computador, e um par de luminárias de mesa. Respeitando o critério da pesquisa quanto a equipamentos acessíveis, a compra de suportes de celular foi descartada, ao mesmo tempo em que se percebeu a oportunidade de produzi-los. As principais técnicas de prototipagem digital e que são encontradas nos FABLABs são: corte a laser, impressão 3D, corte CNC, corte em vinil e fresagem milling ou de precisão (Pupo, 2009).

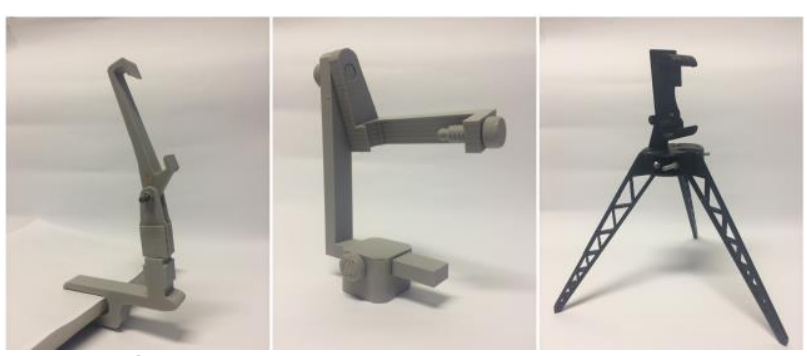

Figura 3: Suporte para smartphones utilizados na oficina. Fonte: autores.

Pela pequena dimensão da peça e pela disponibilidade de material, escolheu-se prototipar os suportes, modelados tridimensionalmente, em impressora 3D de 
filamento, sendo testados e selecionados três modelos para disponibilizar aos grupos, sendo que cada uma poderia escolher seu modelo de suporte e modificá-lo no arquivo digital disponibilizado (imagem 3). A Universidade em que a oficina foi realizada possui um FABLAB, porém, o maquinário, que, de acordo com as pesquisas, seria de menor custo e complexidade, e maior rapidez (corte a laser), estava indisponível.

A fim de cumprir com o papel de integrar os processos manuais e digitais, optou-se pelo processo de modelar tridimensionalmente os projetos e planificá-los para serem impressos em papel e montados manualmente. Para isso, foram escolhidos softwares de fácil aprendizagem, além de gratuitos. A versão gratuita do software SketchUp foi selecionada para a modelagem tridimensional por ser de conhecimento prévio, e o software Pepakura Designer foi escolhido para a planificação do objeto tridimensional pela facilidade de aprendizado.

Para a captura da imagem via celular, foi selecionado um aplicativo que fosse gratuito, de fácil aprendizagem e compatível com sistema Windows e macOS, para computadores, e sistema Androide e iOS para smartphones. Pesquisou-se os 10 primeiros resultados do Google Play Store, sendo selecionado o Estúdio Stop Motion, conforme a Tabela 1. Para a edição das imagens captadas, os softwares Windows Movie Maker e iMovie foram selecionados por serem de fácil utilização e porque os alunos já os tinham em seus computadores, uma vez que fazem parte do pacote de instalação dos respectivos sistemas Windows e macOS.

Tabela 1: Aplicativos de smartphones para produção de animações em Stop motion.

\begin{tabular}{|l|l|}
\hline Aplicativo & Característica eliminatória \\
\hline Estúdio Stop Motion & Nenhuma \\
\hline PicPac & Apenas para Androide \\
\hline Estúdio Stop Motion Pro & Aplicativo pago \\
\hline Stop-Motion - Lite & Problemas para exportar vídeo \\
\hline Stop Motion Maker & Somente em inglês \\
\hline Funmotion & Apenas para Androide \\
\hline Clayframes & Apenas para Androide \\
\hline PicPac Stop Motion Pro & Pago \\
\hline Clayframes - Stop Motion & Pago \\
\hline
\end{tabular}

\section{ESTUDO DE CASO - OFICINA}

Tabela 2: Organização da oficina por dia de atividade.

\begin{tabular}{|l|l|}
\hline Dia & \multicolumn{1}{|c|}{ Descrição das atividades } \\
\hline $\mathbf{1}^{\mathbf{0}}$ & $\begin{array}{l}\text { Aula teórica sobre prototipagem digital. Divisão dos } \\
\text { acadêmicos em grupos. Lançamento do exercício. }\end{array}$ \\
\hline $\mathbf{2}^{\mathbf{0}}$ & $\begin{array}{l}\text { Introdução ao software Pepakura Designer. Início do } \\
\text { desenvolvimento do exercício de prototipagem. }\end{array}$ \\
\hline $\mathbf{3}^{\mathbf{0}}$ & $\begin{array}{l}\text { Continuação do desenvolvimento do exercício, com } \\
\text { orientações. Planificação, impressão e finalização com } \\
\text { a montagem dos protótipos. }\end{array}$ \\
\hline $\mathbf{4}^{\mathbf{0}}$ & $\begin{array}{l}\text { Aula teórica sobre animação. Configuração de } \\
\text { equipamentos, softwares e aplicativos. Gravação de } \\
\text { uma animação como exemplo do fluxo de trabalho. }\end{array}$ \\
\hline $\begin{array}{l}\text { Apresentação de animações em stop motion realizadas } \\
\text { por estudantes e profissionais de arquitetura. } \\
\text { Lançamento do exercício de animação - os grupos têm } \\
\text { que planejar e realizar o projeto por conta própria. } \\
\text { Orientações contínuas com respeito ao ferramental } \\
\text { utilizado e quanto à técnica de animação. }\end{array}$ \\
\hline
\end{tabular}

60 $\quad$ Orientações contínuas com respeito ao ferramental utilizado e quanto à técnica de animação.

70 $\quad$ Apresentação das animações e discussão sobre o papel potencial da animação e prototipagem.

A oficina de animação stop motion e prototipagem teve a duração de sete dias no período matutino, ao longo de duas semanas, com 24 convidados do $5^{\circ}$ período da graduação de Arquitetura e Urbanismo, no primeiro semestre de 2018. A organização da oficina por dia de atividade seguiu o cronograma da tabela 2 .

\section{RESULTADOS E DISCUSSÕES}

A coleta de dados se deu continuamente por meio de observação e documentação (imagem e vídeo-áudio), com o foco de extrair as dificuldades que os discentes tiveram com as ferramentas e o registro das atividades. Também foram aplicados dois questionários semiestruturados com objetivo de compreender quais foram os benefícios da introdução da animação e de integrar processos digitais e manuais nos ateliês de projeto.

\section{OBSERVAÇÃO}

O primeiro dia iniciou com a abordagem do tema prototipagem digital, com exemplos de aplicação na arquitetura por meio de vídeos e livros, e continuou abordando os assuntos: Arquitetura digital; CAD/CAM; Projeto digital; Prototipagem digital; produtos resultantes (protótipos/maquetes); principais técnicas no mercado; Corte a laser; impressão 3D; corte CNC; automatização da arquitetura; tipos de encaixe; Open source / compartilhamento de arquivos; FABLABs; customização em massa; modularização; e exemplos de aplicações na arquitetura internacional, nacional e local. Abordou-se também os cuidados com a produção digital dos arquivos, os principais formatos considerados neutros e que não prejudicam a prototipagem, e ainda os principais erros em relação a produção desses arquivos e como evitá-los, transferindo assim conhecimento sobre o tema e deixando os educandos mais envolvidos no assunto. Após a finalização da parte teórica, os acadêmicos foram divididos em oito grupos de três a quatro pessoas e foi lançado o exercício prático de prototipagem, que consistiu no desenvolvimento de um objeto conceitual e exploratório de livre escolha. O protótipo desenvolvido foi utilizado na segunda semana da oficina na produção das animações stop motion. O primeiro dia foi finalizado com a instalação do software Pepakura Designer e verificação se todos já possuíam o software SketchUp instalado.

No segundo dia de oficina, foi introduzido o software Pepakura Designer, por meio de um exemplo prático. Os graduandos ficaram empolgados pela facilidade do software e a possibilidade de criação rápida de um protótipo para estudo. Seguiu-se com a produção do objeto conceitual do exercício prático de prototipagem, com orientações quando solicitadas. Um passo-a-passo do software Pepakura Designer foi disponibilizado.

O terceiro dia de oficina prosseguiu com 0 desenvolvimento do objeto conceitual. Conforme os alunos terminavam sua planificação, iniciavam a impressão do modelo em papel sulfite, para posterior dobragem manual (Figura 04). Os educandos exploraram a ferramenta, imprimindo modelos, conforme a evolução da ideia de projeto. Três grupos, após a primeira montagem, resolveram imprimir novamente em papel com gramatura maior, para maior estabilidade. Foi um 
processo rápido e prático para o desenvolvimento de protótipos, com grande expressividade de resultados e contribuindo na construção do conhecimento dos acadêmicos quanto à importância dos protótipos e maquetes na construção projetual. No final do terceiro dia, foi solicitado o preenchimento de um questionário online sobre o tema prototipagem e os arquivos digitais dos suportes de smartphones foram cedidos, de modo que as equipes pudessem escolher qual gostariam de utilizar durante a próxima semana.

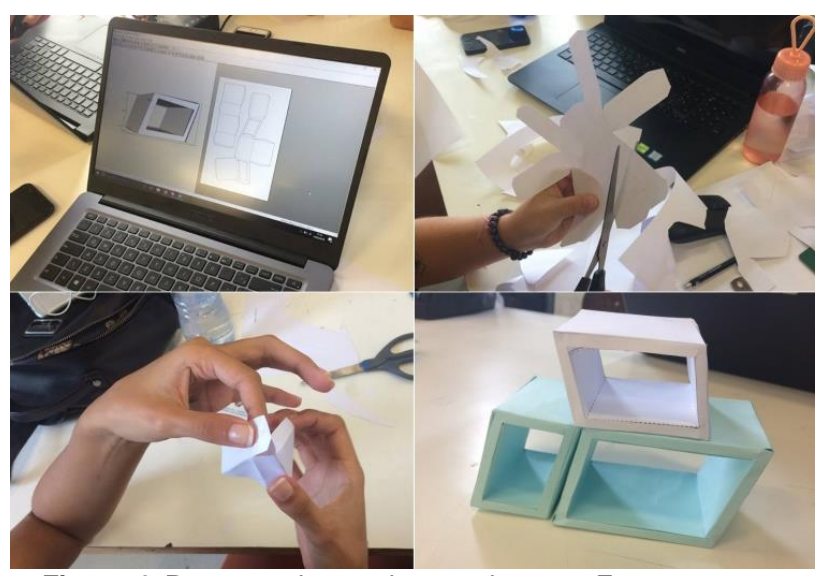

Figura 4: Processo do uso da prototipagem. Fonte: autores.

No quarto dia teve uma introdução sobre animação e sua utilização no ensino de arquitetura e o que já se pesquisou nesse campo. Apresentadas as diversas técnicas de animação, foi exposto o porquê da escolha da técnica em stop motion, e deu-se prosseguimento a respeito do material básico para se fazer uma animação, os softwares necessários e como configurá-los, e por fim, foi dada uma aula sobre noções de fotografia, animação e maquetes, durante a qual os graduandos tiraram dúvidas a respeito da iluminação das animações em stop motion. Os suportes de celular prototipados foram entregues as equipes que os limparam (retirando os suportes da impressão 3D) e os montaram. Enquanto isso, um setup básico para animação foi montado em sala, com duas luzes sobre uma mesa estável e suporte de smartphone fixado à mesa; também foi disponibilizado massa de modelar e um conjunto de silhuetas humanas fabricadas com corte laser na escala 1:50 como material básico para a familiarização com a técnica. Os integrantes dos grupos se surpreenderam com a característica do exercício de absorver a concentração e afirmaram que o exercício flui depois de iniciado e se torna divertido, sendo que foram entregues quatro animações de 4 a 8 segundos, superando as expectativas da programação da oficina. Essas observações estão de acordo com os resultados explorados por Bonanni e Ishii, (2009), que apontam que animações simples e efetivas podem ser feitas em apenas algumas horas. Ao final da manhã, foram informadas do cronograma e da entrega do exercício de animação de no máximo 60 segundos com tema aberto a ser apresentado no último dia da oficina.

No quinto dia, foram exibidos vídeos em stop motion, produzidos por estudantes e profissionais de arquitetura, que foram complementadas com observações em relação a aspectos técnicos das capturas das imagens e sobre as vantagens que a linguagem de animação pode proporcionar para um maior entendimento sobre os projetos apresentados. Após a exibição, os grupos iniciaram seus projetos de animação, tendo trazido seus próprios computadores, smartphones, luminárias, materiais para a produção de modelos e cenários, e trabalharam com os softwares sugeridos. Seguiram diferentes métodos de trabalho: sendo que quatro planejaram várias cenas a fim de contar uma história, os outros quatro decidiram seguir um processo mais aberto, tomando decisões sobre suas animações a medida em que eram produzidas. Todos se preocuparam com a estética da animação, sendo que sete equipes atentaram em produzir planos de fundo para ambientá-las. As escalas das cenografias e bonecos produzidos também divergiram bastante, desde a escala 1:10, onde representam a interação de usuários com mobiliário urbano, até cenários com escalas entre 1:100 e 1:2000. A própria natureza do trabalho com animação permite essa licença poética de transitar entre diversas escalas diferentes e aceitar isso dentro do contexto da animação. Quatro grupos optaram por trabalhar com massinha devido ao custo baixo de aquisição, a estabilidade do material foi solucionada com estruturas internas de arame. Papel, arame e miniaturas prontas foram utilizados para representar pessoas. Houve dúvidas técnicas a respeito dos materiais, meios de fixar os objetos e sobre a captura das imagens.

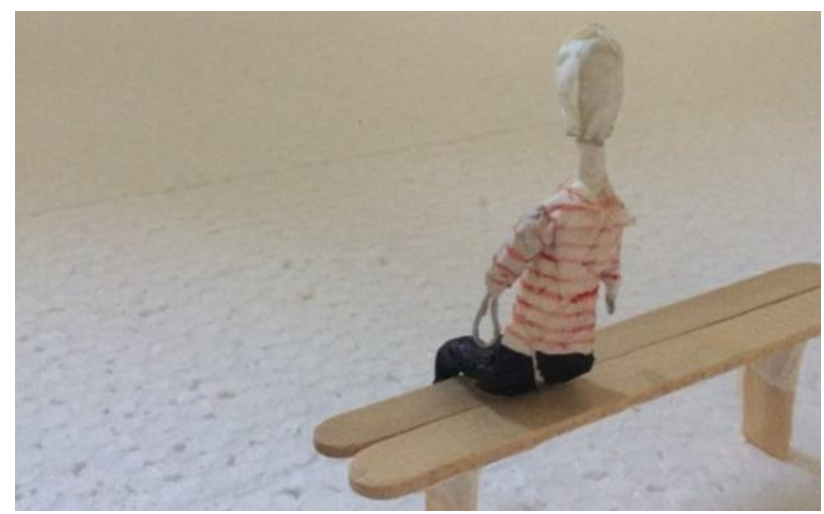

Figura 5: Produção de modelos e cenografia. Fonte: autores.

No sexto dia, foram continuados os trabalhos do dia anterior. Todos apresentavam muito material produzido em forma de modelos e maquetes e ainda continuavam a produzi-los conforme seguia a captura das imagens. Houve algumas dúvidas pontuais sobre o software Movie Maker e dificuldades em manter a iluminação estável. Um indivíduo sugeriu que a oficina tivesse mais aula sobre fotografia. No geral, o clima do ambiente de trabalho esteve bem positivo e os discentes pareciam estar se divertindo apesar da quantidade de trabalho que estavam executando.

No último dia de oficina, cada equipe apresentou a animação produzida e depois comentou sobre o processo, dificuldades que tiveram e o que aprenderam durante a oficina. Houve uma discussão geral sobre 0 conjunto do curso e sobre o potencial da animação e prototipagem como uma forma de auxiliar a projetar em arquitetura. Ao final, foi disponibilizado um link com outro questionário online para ser respondido voluntariamente pelos partícipes, sobre o tema animação. Além disso, imagens da oficina e as animações resultantes foram coletadas e posteriormente disponibilizadas na web em página própria da disciplina cursada pelos estudantes (veja

<https://www.facebook.com/P.IVUFSC2015.1/>). 


\section{QUESTIONÁRIO DE PROTOTIPAGEM}

Com relação ao primeiro questionário, obteve-se o retorno de 13 voluntários. Desses, 38,5\% já tinham utilizado alguma técnica de prototipagem, enquanto o restante não conhecia ou só tinha ouvido falar sobre. Com relação a esses primeiros dias, todos tiveram suas expectativas atendidas e confirmaram que a oficina será útil na vida acadêmica e profissional.

Com relação aos aspectos positivos, os acadêmicos apontaram que os assuntos trazidos foram satisfatórios, suprindo a falta deles no curso de graduação em questão, apontaram também que o conteúdo foi abrangente, diferente e útil. O software Pepakura Designer foi indicado como interessante e de grande utilidade para próximos estudos, conforme relato do participante 11: "foi ótimo pois conseguimos dar forma aos nossos desenhos que antes ficam somente em croquis" e do participante 13: "Possibilidade de conhecer novos meios de projetar; auxiliar melhor no entendimento do objeto ao fabricar seu protótipo; tentativa de maior aproximação da realidade. " Outros relatos abordam a planificação e produção rápida e fácil dos protótipos, a utilização de um novo software e os assuntos tratados. $\mathrm{O}$ aspecto negativo mais citado, por $53,8 \%$, foi o curto tempo da oficina. Outro ponto foi a indisponibilidade do FABLAB da universidade, citado por $23,1 \%$, que não permitiu uma maior aproximação com outras ferramentas para prototipagem, e 7,7\% relatou que não teve aspectos negativos.

Quanto às dificuldades, 61\% afirmou ser difícil o início da utilização do software Pepakura Designer, devido ao pouco tempo de oficina, porém, após orientações, as dúvidas foram esclarecidas. Outra questão abordada por $15,4 \%$ foi a dobragem dos protótipos de papel, que se tornou difícil devido à baixa gramatura inicial utilizada.

Gráfico 1: Utilização da prototipagem nas fases projetuais indicada pelos participantes.

- Apresentação em concursos
Apresentação para o cliente
Detalhamento executivo
Anteprojeto
莭 Estudo preliminar
$\times$ Estudo viabilidade

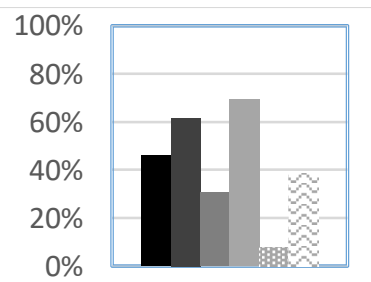

O Gráfico 1 apresenta as opiniões dos convidados quanto às aplicações da técnica de prototipagem nas fases do processo de projeto. Todos concordam que a técnica de prototipagem é indicada no estudo preliminar, afirmando que a prototipagem no presente estudo não é vista somente como um meio de apresentação, mas sim uma ferramenta de avaliação projetual. As limitações foram a disponibilidade de maquinários e a necessidade do conhecimento prévio em softwares específicos. Em relação ao software Pepakura Designer, 76,9\% não o conheciam, porém, todos assentiram que foi útil para criação dos protótipos.

Como contribuições, observações e/ou sugestões, os membros informaram que gostariam de ter tido uma maior aproximação com o FABLAB e maior tempo de oficina, também reafirmaram que a oficina foi ótima para entendimento e produção de protótipos.

\section{QUESTIONÁRIO DE ANIMAÇÃO STOP MOTION}

O segundo questionário teve retorno de 17 pessoas, desses apenas $17,6 \%$ possuíam alguma experiência anterior em animação, e 64,7\% afirmaram ter algum conhecimento prévio sobre captação e edição de vídeo dez declararam trabalhar com Windows Movie Maker, dois com IMove, dois com aplicativos de smartphones e um com Sony Vegas e Adobe Première. Com relação ao tempo de oficina $58,8 \%$ consideraram que foi suficiente para concluir o exercício proposto, enquanto o restante opinou que deveria ter mais um dia. Quanto à dificuldade de animação de objetos em stop motion, 29,4\% responderam ter tido média dificuldade e $70,6 \%$ afirmam pouca dificuldade com a animação. Portanto, apesar de poucos terem um conhecimento prévio sobre animação, a maioria afirmou ter facilidade com a técnica.

Outras dificuldades (Gráfico 2) foram sobre o ferramental, $41,2 \%$ não conseguiram fazer o controle remoto do smartphone via computador devido à falta de sinal de internet wireless da instituição de ensino e 17,6\% tiveram alguma dificuldade com o próprio computador ou na instalação dos softwares. Em relação ao uso dos smartphones, aplicativos e suportes de celular utilizados, $23,5 \%$ relataram ter alguma dificuldade com a estabilidade do suporte. Acerca da iluminação, 41,2\% responderam que tiveram poucos ou nenhum problema, e $58,8 \%$ que havia muita instabilidade de luz, nas palavras do participante 11: "Influência da iluminação do local e da iluminação dos outros grupos acabou dificultando". A respeito da estabilidade das mesas de trabalho, 11,8\% apontaram dificuldades. Em pergunta aberta, 11,8\% relataram dificuldade em fixar modelos e cenários a mesa.

Gráfico 2: Dificuldades apresentadas pelos participantes em relação ao ferramental da oficina de animação.

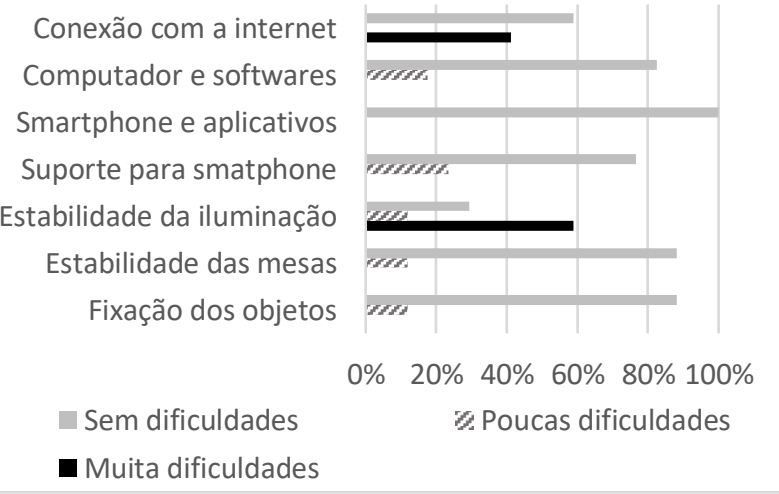

O Gráfico 2 retrata os dois principais problemas apontados pelos partícipes: conexão com a internet wireless e a instabilidade de iluminação gerada pelo fato de todos os grupos terem trabalhado próximos, e pelo fato da sala não ter elementos para barrar completamente a iluminação natural que entra em grande quantidade no espaço.

As perguntas seguiram sobre o uso da animação e sua validade como ferramenta de auxílio no processo de projetar. Com relação a utilidade do stop motion para tornar os modelos e objetos físicos "vivos", houve uma visão concordante em ser muito útil. Inquiridos se a partir 
do momento em que modelos e objetos ganham vida esses levaram o projeto para rumos antes não planejados, 58,8\% responderam sim, que aconteceram algumas mudanças, enquanto 35,3\% afirmam terem seguido um planejamento, e apenas 5,9\% declaram que as mudanças aconteceram constantemente. Os dados estão de acordo com a observação, que registrou que quatro grupos fizeram planejamento de cena, e inclusive um elaborou um roteiro a ser seguido. Zarin, Lindbergh e Fallman (2012), em seu estudo de caso, tiveram resultados similares, em que seus alunos concordaram que o stop motion dá vida aos objetos, e assim revelam novos aspectos e dimensões. Questionados se a animação dos modelos trazia novos entendimentos sobre o projeto, $29,4 \%$ responderam que não trouxe novos entendimentos, 5,9\% respondeu não mas acreditam que possa acontecer, como explica o participante 15: "No caso já imaginávamos as questões que aconteceram, porém, acredito que em certos casos há grande possibilidade de mostrar coisas não vistas anteriormente". Enquanto 64,7\% afirmaram que sim, descrevendo que levavam a pensar em novos usos para o projeto, em como os objetos e as pessoas se relacionavam e em como a temporalidade e o dinamismo passaram a fazer parte do processo de projeto, nas palavras do participante 10: "O dinamismo trazido pelos modelos e objetos ajudaram na percepção de facilidades e dificuldades na área explorada", do participante 12: "Sim, a possibilidade de movimento tornou a ideia de temporalidade mais forte e presente" e do participante 17: "Ao dar vida para um objeto, consequentemente ele terá relações com o seu envoltório, ou seja, passamos a pensar sobre relações que talvez não fossem pensadas caso não ganhassem vida.".

Foi ainda perguntado se consideravam relevante o uso de animação para esboçar arquitetura, 58,8\% responderam que consideraram muito relevante e $41,2 \%$ um pouco relevante. Indagados se achavam que poderiam incorporar o que aprenderam em algum projeto futuro, $41,2 \%$ afirmaram que sim, que gostariam de incorporar essa ferramenta, 52,9\% afirmaram que sim, com a ressalva de considerassem a técnica ou um pouco difícil ou demorada, e apenas 5,9\% responderam que não.

\section{RESULTADOS DAS ANIMAÇÃO STOP MOTION}

As animações produzidas foram analisadas, segundos os critérios: 1 - Aspectos dinâmicos e interativos entre os espaços e seus usuários, incluindo fluxos e movimentos; 2 - Passagens de tempo (horas, dias, anos, séculos) e transições; e 3 - Apresentação de conceitos e ideias de projeto. Do total de oito animação produzidas, seis exploraram aspectos dinâmicos e interativos entre os espaços e seus usuários, incluindo fluxos e movimentos, enquanto duas animações focaram em representar uma longa passagem de tempo, e desta forma trabalharam seus modelos em escalas muito menores, que permitissem mostrar grandes edificações. Em comum, todas as animações procuraram salientar a construção de conceitos e ideias de projeto, como pode ser visto nos quadros retirados de três das animações produzidas na oficina (Figura 6).

As imagens (Figura 6 - A e B) mostram diferentes situações a partir dos módulos desenvolvidos para um mobiliário urbano, construindo diferentes disposições e combinações que formulam situações de uso coletivo ou individual, exploram como as pessoas vão interagir quando sentadas em diferentes locais, mostrando a dinâmica do lugar. Portanto usaram a animação como um método de pensar o projeto e testar diversas possibilidades de forma rápida, como um esboço dinâmico, no qual conseguiram desenhar a ideia dos ambientes, dos lugares que estão criando e mais a dinâmica dos usuários. Esse resultado está de acordo com o registrado por Fallman e Moussette (2011), na visão dos autores a animação stop motion deve ser explorada em seu potencial como uma ferramenta de esboço, ou seja, como uma técnica pelo qual conceitos e ideias não são apenas apresentados, mas gerados.
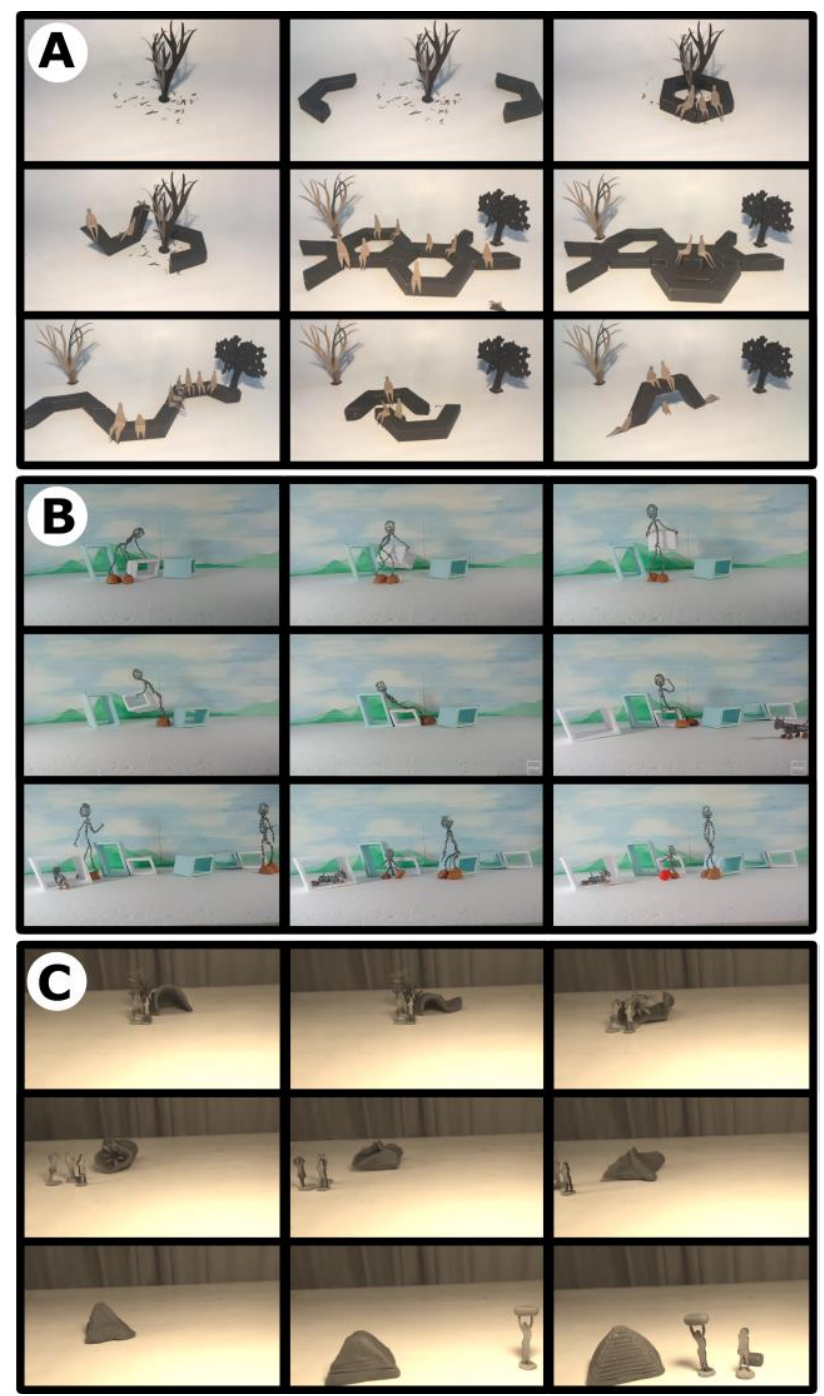

Figura 6: A e B - quadros de animações que destacam aspectos dinâmicos e interativos entre os espaços e seus usuários. C . quadros de uma animação que focou em representar conceitos de arquitetura ao longo da história. Fonte: autores.

Outra animação (Figura 6 - C) produzida explorou a história da arquitetura através do uso de símbolos e conceitos, com aspectos conceituais. Bonani e Ishii (2009) apontam que as animações stop motion tornam relativamente fáceis de acelerar ou reverter o tempo e dar propriedades mágicas aos objetos inanimados, incentivando o trabalho altamente imaginativo. O grupo que a produziu escolheu não continuar com os protótipos de papel pelo fato de terem uma certa limitação na forma devido a montagem manual. Escolhendo trabalhar com massa de modelar exploraram características próprias da 
animação como a metamorfose, fazendo com que as construções surgissem e se dissolvessem no cenário ou se metamorfoseiam em outras construções, trazendo o significado de arquitetura como algo mutável no tempo.

\section{CONCLUSÕES}

A animação e a prototipagem nesse estudo de caso se mostraram muito relevantes para esboçar arquitetura, de modo que possibilitou novas formas de representar e entender o processo de projeto, contribuindo para uma formação acadêmica e profissional dentro do contexto atual e das ferramentas digitais. A prototipagem permitiu que os modelos gerados tridimensionalmente fossem facilmente materializados e testados, e, se necessário, reajustados, o que encorajou os alunos a testarem suas ideias. Também deu suporte ao ferramental básico necessário para a oficina de animação.

A animação permitiu explorar elementos que dificilmente seriam explorados tão profundamente com outro ferramental em tão curto espaço de tempo, como as transições e passagens de tempo, o fluxo de pessoas através do espaço construído e os aspectos dinâmicos e interativos entre o lugar e seus usuários. Também se mostrou relevante como uma forma de esboço dinâmico no qual diversas ideias de projeto puderam ser testadas de maneira rápida com um registro (o vídeo da animação) que permitiu sua posterior avaliação pelos autores.

O fato de toda a oficina ter sido elaborada com ferramental acessível, com equipamentos fáceis de configurar e sem requerer grande conhecimentos a priori, fez com que fosse bem aceita pelos discentes, sendo considerada relevante e ao mesmo tempo divertida de ser realizada, principalmente como trabalho de equipe. Além disso, apresentam um resgate da maquete física nas escolas, porém inserindo tecnologias digitais.

O uso dos softwares para a modelagem e posterior planificação do projeto para ser impresso e montado mostrou-se de grande aceitação pelos educandos, apesar da dificuldade inicial, para um próximo estudo de caso, o objetivo será focar mais no ensino do programa de planificação. Quanto à animação, a maior dificuldade foi com relação à instabilidade da luz, portanto, considera-se de grande relevância a disponibilidade de um local adequado para uma futura oficina.

\section{AGRADECIMENTOS}

Agradecemos à CAPES pelo financiamento desta pesquisa, e ao laboratório Pronto 3D Unochapeco pela prototipagem dos suportes de celular utilizados na oficina.

\section{REFERÊNCIAS}

Alexander, C. (1979). The timeless way of building. New York: Oxford University Press.

Batistello, P., Balzan, K. L., Piaia, L. P., \& Miotto, J. (2015). Prototipagem rápida e fabricação digital em ateliê vertical: do processo à materialização Paper presented at the XIX Congresso da Sociedade Ibero-Americana de Gráfica Digital - Sigradi, Florianópolis.
Bonanni, L. A., \& Ishii, H. (2009). Stop-Motion Prototyping for Tangible Interfaces. Paper presented at the Third International Conference on Tangible and Embedded Interaction, Reino Unido. doi: 10.1145/1517664.1517729

Digital Design Fabrication Group. Retrieved from http://ddf.mit.edu/

Dollens, D. (2006). The Cathedral is Alive: Animating Biomimetic Architecture. Animation: an interdisciplinary journal, 01, 105117. doi: $10.1177 / 1746847706065844$

Eikenes, J. O. H., \& Morrison, A. (2010). Navimation: Exploring Time, Space \& Motion in the Design of Screen-Based Interfaces. International Journal of Design, 04, 01-16.

Fallman, D., \& Moussette, C. (2011). Sketching with Stop Motion Animation. Interactions, 18, 57-61. doi: 10.1145/1925820.1925833

Kowaltowski, D. C. C. K. B., Giovanna, \& Petreche, J. R. D. (2011). A Criatividade no processo de projeto. In O processo de projeto em arquitetura: da teoria à tecnologia (pp. 21-56). São Paulo: Oficina de Textos.

LAPAC - Laboratório de Automação e prototipagem para arquitetura e construção. Retrieved from http://lapac.fec.unicamp.br/

Laybourne, K. (1979). The animation book: a complete guide to animated filmmaking, from filp-books to sound cartoons. New York: Crown Publishers.

Lindell, R. (2012). Pining for the Materiality of Code, From Materials to Materiality: Connecting Practice and Theory in $\mathrm{HCl}$. Paper presented at the Austin, Texas, USA., Conference on Human Factors in Computing Systems (CHI) http://www.es.mdh.se/pdf_publications/2450.pdf

Lord, P., \& Sibley, B. (2010). Cracking animation (New ed.). London: Thames \& Hudson.

Nardelli, E. S. (2014). Fabricação Digital na Produção de Habitação de Interesse Social no Brasil. Paper presented at the Congreso de la Sociedad Iberoamericana de Gráfica Digital - Sigradi, Uruguay.

Pina, S. A. M. G., Borges Filho, F., \& Maragoni, R. F. (2011). Maquetes e modelos como estímulo à criatividade no projeto arquitetônico. In $\mathrm{O}$ processo de projeto em arquitetura: da teoria à tecnologia (pp. 109-123). São Paulo: Oficina de Textos.

Pupo, R. (2008). Ensino da prototipagem rápida e fabricação digital para arquitetura e construção no Brasil: definições e estado da arte. PARC, 1(3), 80 - 98. doi:10.20396

Pupo, R. (2009). Inserção da PROTOTIPAGEM e FABRICAÇÃO DIGITAIS no processo de projeto: um novo desafio para o ensino de arquitetura. (Doutorado), Universidade Estadual de Campinas, Campinas.

Sass, L. (2008). Parametric constructionist kits: Physical design and delivery system for rapid prototyping devices. International Journal of Architectural Computing, 07,623-642.

UIA, A. d. (2011). Carta para a Educação dos Arquitetos. Retrieved from Barcelona, Espanha: http://cialp.org/documentos/1439567302V4pFQ3qn3Jd55EK $0 . p d f$

Ylirisku, S., \& Buur, J. (2007). Designing with video: focusing the user-centred design process. London: Springer.

Vistisen, P. (2016). Sketching with animation: using animation to portray fictional realities - aimed at becoming Factual. Aalborg: Aalborg Universitetsforlag.

Zarin, R., Lindbergh, K., \& Fallman, D. (2012). Stop Motion Animation as a Tool for Sketching in Architecture. Paper presented at the DRS 2012 Bangkok, Thail 